Published in final edited form as:

Sex Res Social Policy. 2019 ; 16(4): 408-418. doi:10.1007/s13178-018-0356-7.

\title{
TransAction: A homegrown, theory-based, HIV risk reduction intervention for transgender women experiencing multiple health disparities
}

\author{
Cathy J. Reback ${ }^{1,2,3}$, Kirsty Clark $^{4}$, Jesse B. Fletcher ${ }^{1}$ \\ ${ }^{1}$ Friends Research Institute, Inc., Los Angeles, CA \\ ${ }^{2}$ Integrated Substance Abuse Programs, Semel Institute for Neuroscience and Human Behavior, \\ University of California, Los Angeles, CA \\ ${ }^{3}$ Center for HIV Identification, Prevention and Treatment Services, University of California, Los \\ Angeles, CA \\ ${ }^{4}$ Department of Epidemiology, Fielding School of Public Health, University of California, Los \\ Angeles, CA
}

\begin{abstract}
HIV vulnerability among transgender women is symptomatic of numerous syndemic psychosocial and structural co-factors that attribute to and exacerbate HIV risk. From February 2010 to December 2017, 514 transgender women enrolled in a 'homegrown' theory-based, HIV risk reduction program, TransAction, specifically designed to intervene with trans women who experience numerous co-occurring health disparities. Increased attendance in TransAction intervention sessions was associated with significant reductions in the number of male sexual partners (coef. $=-0.20$ ), anonymous male sexual partners $(-0.30)$, exchange male sexual partners $(-0.25)$, engagement in drug/alcohol use (-0.37), engagement in injection drug use $(-0.20)$, engagement in unmonitored injection hormone use (-0.55), engagement in sex while high $(-0.23)$, and engagement in sex work $(-0.20$; all coefficient estimates $\mathrm{p} \leq 0.05)$. Results demonstrated that the homegrown HIV risk reduction intervention was successful in working with transgender women who experience multiple co-occurring syndemic conditions. Given that there has been a dearth of evidence-based interventions for this population that are designed to be delivered in resource limited settings, TransAction can serve as a model HIV risk reduction program for guiding public health departments and community-based organizations.
\end{abstract}

Corresponding Author: Cathy J. Reback, Ph.D., 1419 La Brea Ave., Los Angeles CA 90028, reback@ friendsresearch.org, phone: (323) 463-1601.

Conflict of interest: The authors declare that they have no conflict of interest.

Compliance with Ethical Standards

Research Involving Human Participants: All procedures performed in studies involving human participants were in accordance with the ethical standards of the institutional and/or national research committee and with the 1964 Helsinki declaration and its later amendments or comparable ethical standards.

Informed Consent: As outlined in the HHS Office for Protection from Research Risks guidance, the data collected for this manuscript were part of a service program and, thus, exempt from IRB review. 


\section{Keywords}

transgender; HIV; health disparities; risk reduction

\section{Introduction}

\section{Syndemic HIV risks among trans women}

Transgender women (hereafter: trans women) are at tremendous risk of HIV infection compared to their cisgender counterparts (Baral et al., 2013; De Santis, 2009). A recent meta-analysis investigating HIV vulnerability among trans women in the U.S. showed that, on average, a HIV positivity rate of between $18.4 \%-25.1 \%$ compared to approximately $0.81 \%$ among other adult U.S. populations (Baral et al., 2013). HIV vulnerability among trans women is symptomatic of the interaction of numerous psychosocial and structural cofactors that attribute to and exacerbate HIV risk, often referred to as a syndemic. A co-factor is a contributory cause of a disease. Syndemic theory posits that the compounding interaction of two or more co-occurring health problems produces excess disease burden in a population (Singer \& Clair, 2003). As such, synergistic and cyclical interactions of numerous co-factors exacerbate trans women's vulnerability to HIV infection, including documented increased rates of homelessness (Fletcher, Kisler, \& Reback, 2014; Spicer, 2010), substance use disorders (Glynn \& van den Berg, 2017; Nemoto, Hsueh, Steuerman, McCree, \& Horne, 2007; Reback \& Fletcher, 2014), sex work (Operario, Soma, \& Underhill, 2008), victimization and violence (Lombardi, Wilchins, Priesing, \& Malouf, 2002; Stotzer, 2009), mental health disorders (Mustanski, Garofalo, \& Emerson, 2010; Xavier, Bobbin, Singer, \& Budd, 2005), reduced access to health care (Jaffee, Shires, \& Stroumsa, 2016; White Hughto, Murchison, Clark, Pachankis, \& Reisner, 2016), incarceration (James et al., 2016), unsafe or medically unmonitored gender-confirming procedures (i.e., hormone misuse, silicone filler injections) (Clark, Fletcher, Holloway, \& Reback, 2018), and increased stigma, discrimination and transphobia (White Hughto, Reisner, \& Pachankis, 2015). These numerous co-factors foster a syndemic of HIV risks as each of these co-factors is a direct or indirect pathway to HIV acquisition and transmission. There have been numerous quantitative investigations of syndemic conditions on HIV transmission risk behaviors among men who have sex with men (MSM) (Parsons, Grov, \& Golub, 2012; Parsons et al., 2017; Stall et al., 2003). More recently, researchers have applied this quantitative lens to trans women (Nuttbrock et al., 2014). For example, Parsons et al. (2018) conducted a quantitative investigation of syndemic conditions among trans women and found that trans women who experienced four syndemic conditions (i.e., polydrug use, depression, childhood sexual abuse, and intimate partner violence) demonstrated 8.84 times the risk of engaging in recent HIV transmission risk behaviors compared to trans women who had experienced no syndemic conditions (Parsons, Antebi-Gruszka, Millar, Cain, \& Gurung, 2018).

Trans women who engage in sex work, and/or are experiencing housing insecurity, and/or substance use are at particularly salient risk of the syndemic dynamics in the increased risk of HIV infection and engagement in HIV risk behaviors (Operario et al., 2008; Poteat et al., 2015; Wilson et al., 2009). Qualitative interviews with trans women of color engaged in sex 
work $(\mathrm{N}=48)$ found that the main motivators for sex work involvement were a host of structural and economic barriers (Sausa, Keatley, \& Operario, 2007). Interviews revealed the synergistic interaction between psychosocial and structural factors and the consequent influence on HIV risk. For example, due to social marginalization and employment discrimination, trans women were often forced out of the legal economy and into survival sex work, where they sometimes used substances to cope with depression and other mental health concerns, were often homeless or unstably housed due to limited income and/or housing discrimination, and had less power in condom use negotiations with clients upon whom they relied for income and other basic needs. Given that almost all of these HIVrelated co-factors were inter-related, the authors' surmised that the co-occurrence of these factors was inevitable, and their attribution to HIV risk was exacerbated, thus characterizing the syndemic dynamics at play in trans women's heightened vulnerability to HIV transmission and infection.

Transgender health experts have emphasized that the multi-component nature of HIV risk in trans communities requires a departure from conventional HIV prevention interventions that have traditionally focused almost completely on condom use, HIV prevention knowledge, and safer sex (Operario \& Nemoto, 2010). Indeed, without addressing the syndemic psychosocial and structural factors that contribute to and compound HIV vulnerability among trans women, interventions are unlikely to succeed in reducing HIV risk. In particular, interventions attuned to the syndemic dynamics of HIV risk among trans women are essential for trans women who experience multiple co-occurring predictors (e.g., housing insecurity, substance use disorders, mental health disorders, engagement in sex work, cycles of incarceration) of HIV acquisition and transmission (Clements-Nolle, Marx, Guzman, \& Katz, 2001).

\section{HIV risk reduction interventions among trans women}

There are only a few HIV risk reduction interventions specifically designed to intervene among trans women. Bockting and colleagues developed a two-day workshop adapted from the Sexual Health Model (Robinson, Bockting, Simon Rosser, Miner, \& Coleman, 2002) that addressed condom use, safer sex efficacy, and sexual risk behavior among trans people in Minneapolis, Minnesota (Bockting, Robinson, Forberg, \& Scheltema, 2005). The intervention was adapted and developed through focus groups with trans community members who identified numerous co-factors for HIV risk including discrimination, violence, loneliness, and transphobia, which were then structured into the workshop. Prepost test results $(\mathrm{N}=181)$ demonstrated that attitudes towards condom use improved at immediate post-test and at three-month follow-up, but that improvements in safer sex selfefficacy had waned by three-month follow-up. Furthermore, the sample included both trans men and women, was majority Caucasian/White (93\%) and highly educated (73\% completed some college), suggesting that the results might not be generalizable to a higher risk, more diverse sample of trans women.

Taylor and colleagues developed a similar HIV risk reduction intervention based on the Information Motivation Behavior (IMB) model (Fisher \& Fisher, 2002) that was adapted and conducted across four small group sessions with trans women in Jersey City, New Jersey (N 
= 55) (Taylor, Bimbi, Joseph, Margolis, \& Parsons, 2011). Sample demographics characterized a demonstrably higher risk population than Bockting and colleagues; participants were majority non-White $(94 \%)$, low income $(54 \%<\$ 10,000$ per year), and nearly half had not completed high school/GED (46\%). Results from the three-month follow-up found significant reductions in number of sexual partners and unprotected anal/ vaginal intercourse at last sexual encounter, but no differences in unprotected anal intercourse with main or casual partners, a primary HIV transmission risk pathway among trans women (Brennan et al., 2012; Herbst et al., 2008).

Nemoto and colleagues developed a longer-term workshop-based intervention aimed at addressing overall health of trans women in San Francisco, California, including HIV risk (Nemoto, Operario, Keatley, Nguyen, \& Sugano, 2005); the intervention offered 18 one-hour group workshops throughout the year focused around three domains (i.e., sex, relationships, and health; drug use and coping skills; general life needs). Of participants who graduated from the program after completing 10 workshops $(\mathrm{N}=109)$, results were mixed; there were significant reductions in levels of sexual risk during the past 30 days but no changes in illicit drug use or HIV knowledge. Furthermore, participant demographics were not included in the report; thus, generalizability of results is unknown.

Despite some positive reductions in sexual risk behaviors at follow-up across the aforementioned studies, to our knowledge, none of these interventions have been widely disseminated or evaluated in additional diverse samples of trans women. Additionally, the interventions referenced above were not specifically designed and adapted to meet the needs of trans women embedded within syndemic systems of HIV risk. More recently, however, a quantitative syndemic analysis from a multicomponent intervention targeting trans women with multiple co-occurring health disparities demonstrated that having numerous syndemic conditions compounds HIV risk behavior (Parsons et al., 2018). Reback and colleagues developed a ten-session, intensive one-on-one prevention case management program targeting trans women experiencing multiple co-occurring health disparities (Reback, Shoptaw, \& Downing, 2012). The intervention $(\mathrm{N}=60)$ demonstrated a decrease in homelessness and sex work, and an improvement in reported mental health symptomology across the intervention timeline. These results highlighted that interventions can be successful even among populations of trans women experiencing multiple syndemic health conditions; however, less intense interventions might be required for participant retention and program sustainability in lower-resource settings.

There is one known randomized controlled trial of a HIV prevention intervention with highrisk young trans women (ages 16-29) in a culturally tailored, six-session group format with longer-term follow-up (12-months) (Kuhns, Mimiaga, Reisner, Biello, \& Garofalo, 2017). While the pilot study $(\mathrm{N}=51)$ from which the randomized controlled trial was based showed positive reductions in sexual HIV risk behaviors and high feasibility among participants (Garofalo et al., 2012), the intervention was specifically geared towards adolescent and young adult trans women and may not be applicable to adults.

The current literature on HIV risk reduction interventions with trans women highlights a lack of interventions specifically designed for trans women who experience numerous co- 
occurring health disparities and that can be delivered in resource limited settings, as opposed to large randomized controlled trials. Major metropolitan cities in the U.S. have identified numerous syndemic co-factors that contribute to trans women's high risk for HIV infection including substance use, cycles of incarceration, engagement in sex work, mental health disorders, unemployment, sexually transmitted infections (STIs), poverty, stigma and discrimination, transphobia, racism, immigration status, language barriers, low educational attainment, violence and sexual assault, and housing instability (Los Angeles County Commission on HIV and the Los Angeles County Department of Public Health Division of HIV and STD Programs, September 2016). Thus, the lack of risk reduction interventions designed for trans women embedded within systems of syndemic co-factors is a major gap in the HIV prevention toolbox. This study reports the observed effects of a communitybased, homegrown, theory-based, low-intensity, HIV risk reduction program, TransAction, specifically designed to intervene with trans women who experience a syndemic of health disparities. Homegrown interventions are locally developed or adapted, are typically health education or risk reduction interventions, and are targeted to specific populations and groups (Grossman et al., 2011). A central focus of all of the TransAction program components was the link between trans-specific transitional issues, substance use, sexual risk behaviors, and the HIV syndemic factors that influence risk behaviors.

\section{Method}

\section{Participants}

Participants were self-identified trans women (N=514) who attended the TransAction program in the Hollywood/West Hollywood area of Los Angeles County. Anyone that selfidentified as a trans woman (i.e., assigned male sex at birth), regardless of her stage of gender transition, was eligible for program enrollment.

Procedure

Data were collected for eight years, from February 2010 through December 2017. Potential participants were recruited to the TransAction program by teams of trans-identified outreach workers who canvassed areas known to be frequented by trans women including bars, clubs, boutiques, parks, street corners, cruising boulevards, hotels, and hair and nail shops. Any trans woman who attended at least one individual risk reduction counseling session or one group session was considered a program participant.

Participants could earn up to $\$ 50.00$ in gift cards as an incentive for program participation (\$5.00 gift cards distributed at the first, second and third individual risk reduction counseling session, at the 30-, 60-, and 90-day individual sessions follow-up assessments, at the first, second and third group sessions, and at the 30-day group follow-up assessment). All materials were approved by the Los Angeles County, Department of Public Health, Division of HIV and STD Programs.

\section{Theoretical mechanisms of behavior change}

TransAction was premised on four mechanisms of behavior change, each of which was informed by an established body of theoretical and empirical research: 
Social Cognitive Theory: Social cognitive theory (Bandura, 1991, 2001) informed TransAction through its focus on the role of self-monitoring, self-regulation, self-esteem, and self-efficacy in explaining healthy behavior change. Social cognitive theory suggests that increased perception of one's self-worth (i.e., improved self-esteem) coupled with increased belief in one's personal agency (i.e., improved self-efficacy) leads to increased self-monitoring and self-regulation, which promotes the enactment of healthy behavior.

Health Belief Model: The Health Belief Model (Rosenstock, Strecher, \& Becker, 1988) contributed to the content and structure of TransAction through the introduction of information on the health risks facing communities of trans women (e.g., substance use, medically unmonitored hormone use, engagement in sex work), information on how to avoid or reduce such risks, as well as the benefits of healthier lifestyle choices. The Health Belief Model, like Social Cognitive Theory, also informed TransAction through its focus on selfefficacy as a mechanism vital to behavior change; participants' perceived barriers to healthier action are discussed and made manageable at each stage of the program.

Presentation of Self and Identity Management: A critical component of TransAction involves providing insights, information, and instruction on how participants might best present their gender identity to family, friends, co-workers, and their immediate environment. Presentation of self and identity management (Ellemers, 1993; Schlenker, 2012) program components focus on both pragmatic (e.g., how to update one's DMV-issued driver's license to accurately reflect one's gender, how to manage stigma/transphobia/transprejudice) and stylistic (e.g., make-up and hair suggestions, tips on how to dress, speak, and interact during a job interview, medical gender transition options including pros/cons of each procedure) issues important to program participants. Similarly, belief in one's fundamental self-worth (i.e., self-esteem) as well as belief in the ability to change one's circumstances through action (i.e., self-efficacy) are considered both critical outcomes and critical mechanisms in Presentation of Self and Identity Management.

Social Support Theory: A fundamental purpose of TransAction is to increase perceived social support among program participants, a mechanism derived from the insights of Social Support Theory (Shumaker \& Brownell, 1984; Thoits, 1986). Social Support Theory suggests that the perception of love, acceptance, and high esteem from significant others acts as a buffer against stress, self-harm, and the enactment of harmful behaviors. Given that trans women disproportionately experience familial rejection, bullying at school, employment discrimination, domestic violence, and housing insecurity (Grant et al., 2011; James et al., 2016; White Hughto et al., 2015), it is critical that a program designed to promote healthy behavior among trans women also promote social support among its participants. Social support in TransAction came in three primary forms: 1) informational (e.g., discussion of local services and agencies which are trans-competent or cater to trans specific needs, grooming tips); 2) emotional (e.g., transitional life skills, support groups); and, 3) instrumental (e.g., a free daily hot meal, educational and/or workplace support). 


\section{Intervention}

TransAction was developed in 1995 (by the first author), in collaboration with trans women in Los Angeles County. TransAction is a 'homegrown' intervention specifically designed to meet the needs of a population of trans women in the urban core of the Hollywood/West Hollywood/Downtown areas in Los Angeles County, many of whom experience syndemic HIV risk factors. To date, TransAction has been the longest running service program for trans women in Los Angeles County and has been running, with uninterrupted public funding, for over 20 years.

TransAction is a multi-tier HIV risk reduction intervention that utilizes both individual- and group-level interventions. The program consists of a comprehensive, culturally appropriate, continuum of services that include street- and venue-based outreach, one-on-one peer-led individual risk reduction counseling sessions, daily group sessions, and quarterly social events. All intervention components were designed to reduce HIV sexual risk behaviors and increase healthy transgender transition options. All components of TransAction were facilitated by teams of two ethnically diverse, indigenous, trans peer staff. All staff received 6-to-8 weeks of intensive training (from the first author) and demonstrated proficiency in outreach strategies such as how to approach potential participants, group facilitation, establishing trust and rapport among high-risk participants, administering brief assessments, culturally appropriate referrals, and protecting human subjects.

The individual risk reduction counseling sessions allowed the trans peer staff to fully assess participants' needs, make appropriate referrals and, when necessary, direct participants to a higher intensity intervention. In addition to assessing a participant's HIV risk behaviors, topics discussed included ART medication and adherence; PrEP uptake, adherence and persistence; trans assimilation versus disclosure; family relationships; sexuality; and transphobia. Individual risk reduction counseling sessions were client-centered and the topics discussed were guided by each participant's needs and/or requests for information and/or referrals.

Groups were conducted daily at 6:00 PM and a full hot meal was served prior to each group. Transitional Life Skills Groups were conducted on Mondays and provided a context for transition expression related to hair, cosmetics, clothing and hygiene. The Transitional Life Skills Group offered a space whereby participants cultivated their voices and expressed their life experiences as related to their transition process. Skills-building Groups were facilitated on Tuesdays and Thursdays. The Skills-building Groups were manual-driven and the group topics included: Changing Your Name and Gender; Entering the Work Force or Continuing Your Education; Gender Transition Options; HIV and Other STIs; Safer Sex Work and Safer Dating; Self-esteem and Transphobia; and Violence Against Trans Women. The Skillsbuilding group topics were decided upon by trans women who participated in community focus groups, which were held annually since 1995 to solicit input. And, since 1995, the Skills-building Group topics have been updated approximately every five years based upon the feedback from the trans participants in community focus groups. The Skills-building topics were chosen to meet the specific needs of trans women experiencing multiple cooccurring health disparities and to provide HIV information that was directly relevant to trans-specific issues such as the effects of ART or PreP on cross-sex hormone therapy, the 
effects of substance use on cross-sex hormone therapy, staying safe while engaging in sex work, how to access low-cost gender transition documents, and how to protect one's self against hate crimes and sexual/physical assault. Open Discussion Groups were facilitated on Wednesdays and Fridays. Participants were provided a safe environment, within a hightolerance setting, to openly discuss high-risk behaviors. HIV risk co-factors, HIV risk reduction, and health disparities such as transphobia, stigma, racism and discrimination were addressed within each group format.

Quarterly social events were designed to convey health information, prevention messages, and foster social support in a festive, party-style atmosphere. A meal was served at each social event and participants participated in HIV/STI-related games, which included prizes for correct answers. HIV and multiple morbidities counseling and testing were available at the social events. The social events were held to coincide with holidays or community events such as a Valentine's Day event in February, a HIV testing event during National HIV Testing Week in June, and a Halloween event in October.

Participants could attend an unlimited number of group sessions; however, assessments were only conducted during the first and third groups and at 30-day follow-up. Participants could attend a maximum of three individual risk reduction counseling sessions; if additional services were required, participants were then referred to a more intensive program onsite or offsite. Assessments were conducted during the three individual risk reduction counseling sessions and at the follow-up time points at 30,60 and 90 days. Given the sometimes erratic nature of the lives of some trans women, TransAction was designed so that the individual risk reduction counseling sessions and group session could be attended in any order.

\section{Measures}

Behavioral Risk Assessment (BRA).-The BRA is a 13-page HIV risk assessment, designed by the first author (Reback, 2005), that records data on participants' sociodemographic characteristics (e.g., gender identity, sexual identity, age, race/ethnicity, HIV status, educational attainment, housing status, insurance coverage), substance use in the previous 30 days (injection and non-injection drug use and safe needle use protocol), number and gender of sexual partners in the previous 30 days (main, casual, anonymous, exchange (i.e., sex work), and male, female, trans feminine), and details about the participants' three most recent sexual encounters within the previous 12 months (partner type, number or partners in the encounter, HIV status of partner(s), sexual activities during the encounter, substance use by participant and partner(s), location of sexual encounter). Additionally, the BRA includes a section on self-reported risk behaviors which are included in a list format at the end of assessment. For example, participants were asked which of the following risk behaviors they were currently engaged in: anonymous sexual partners; multiple sexual partners; sex work; inconsistent condom use; sex at a commercial sex venue (i.e., a bathhouse or sex club) or at a public sex environment (i.e., a public park or public restroom); substance use; sex while 'high'; injection drug use; injection street hormones; other needle use. All categories were not mutually exclusive.

Each participant was included in the data up to four times, chronologically and all within a single calendar year, once for each assessment carried out during administration of 
TransAction (i.e., at the first and third group intervention, and at the first and third individual intervention). Using a unique identifier to ensure anonymity, staff recorded participant responses on a paper BRA instrument that was subsequently scanned into an optical mark reader (i.e., Scantron) for translation into an electronic database. Given that TransAction was not a closed intervention with a specific mandatory session schedule with a specified time period, the duration of time between each assessment varied by participant. All data were self-reported.

\section{Statistical Analysis}

Descriptive statistics were calculated for participant sociodemographics, program attendance, and self-reported risk behaviors. Specific statistics reported were chosen based on the level of measurement of the variable in question, with means and standard deviations provided for numeric variables and counts/percentages provided for all categorical variables. Multivariate analyses were conducted using population-averaged, robustly estimated general estimating equations employing the negative binomial (for counted outcome variables) and logistic (for dichotomous outcomes) link functions; all analyses adjust for repeated measurements across time through the use of cross-sectional time-series regressions, and adjust for participant racial/ethnic identities, age, and HIV status. Controls were chosen based on literature demonstrating covariate associations with substance use and/or sexual risk-taking among trans women (Herbst et al., 2008; Raiford, Hall, Taylor, Bimbi, \& Parsons, 2016; Reback \& Fletcher, 2014). The primary outcome variable was intervention exposure, as operationalized by the total number of intervention visits (up to four; coded 1 , $2,3,4)$ attended by a participant. All analyses were conducted using Stata v13SE, results were flagged beginning at $\mathrm{p} \leq 0.05$, and all significance tests were two-tailed.

\section{Results}

Five-hundred and fourtneen participants attended a total of 1,156 individual and/or group program visits (range $=1$ thru 4 ; average $=2.25$ ) during the observation period; 103 participants (20\%) attended the maximum of four program visits (i.e., two group and two individual sessions) within a single calendar year, and two-thirds of all participants attended at least two program visits.

As shown in Table 1, participants predominantly identified as African American/Black (31.1\%), Hispanic/Latina (28.8\%), or reported a multiracial/other race identity (27.6\%). Average participant age was 33 years $(\mathrm{SD}=11.5)$, and $95.2 \%$ of participants reported having an educational attainment of a high school diploma/GED or less. More than half $(52.0 \%)$ reported experiencing homelessness in the past 12 months, and $29.2 \%$ reported having been incarcerated in the past 12 months. Almost one-third of the participants reported a HIVpositive serostatus (28.4\%). In both the Open Discussion Groups and in the individual risk reduction counseling sessions, participants raised topics for discussion that were most important and relevant to them. In all cases, topics raised were recorded by category. The topics of discussion initiated by participants at their first visit, followed by the percentage of participants who initiated that topic, were: self-esteem (82\%), emotional support (15\%), social support (15\%), HIV education (10\%), housing support (9\%), sex work (7\%), 
socialization (6\%), interpersonal relationships (5\%), hygiene/grooming (4\%), hormone therapy (4\%), sexuality (4\%), and substance abuse education (4\%).

Table 2 summarizes participants' self-reported sexual partnering in the past 30 days and risk behaviors reported at each program visit. From the first visit through the fourth visit, participants reported reductions in the number of male sexual partners in the past 30 days (Mean $=6.4$ vs. Mean $=3.2$ ), the number of anonymous male sexual partners in the past 30 days (1.2 vs. 0.6), and the number of exchange sex male sex partners in the past 30 days (6.0 vs. 1.7). The percentage of participants at each visit that reported drug/alcohol use (73.0\% vs. $68.1 \%)$, injection drug use (11.5\% vs. $7.8 \%)$, medically unmonitored injection hormone use (9.3\% vs. $1.0 \%)$, engagement in sexual intercourse while 'high' (54.9\% vs. $52.4 \%)$, and engagement in sex work (44.8\% vs. $35.0 \%$ ) all reduced from the first visit to the fourth visit.

Table 3 provides adjusted associations between intervention attendance and these same sexual partnering and risk behavior outcomes, adjusted for participant sociodemographics and repeated measures over time $(\mathrm{n}=512)$. Increased attendance in TransAction intervention sessions was associated with significant reductions in the number of male sexual partners (ARR $=-0.20 ; \mathrm{p} \leq 0.001)$, anonymous male sexual partners $(\mathrm{ARR}=-0.30$; $\mathrm{p} \leq 0.01$ ), exchange male sexual partners ( $\mathrm{ARR}=-0.25 ; \mathrm{p} \leq 0.001)$, drug/alcohol use (AOR $=-0.37 ; \mathrm{p} \leq 0.001)$, injection drug use ( $\mathrm{AOR}=-0.20 ; \mathrm{p} \leq 0.05)$, unmonitored injection hormone use ( $\mathrm{AOR}=-0.55 ; \mathrm{p} \leq 0.001$ ), sex while under the influence of alcohol/drugs $(\mathrm{AOR}=-0.23 ; \mathrm{p} \leq 0.001)$, and engagement in sex work ( $\mathrm{AOR}=-0.20 ; \mathrm{p} \leq 0.001)$. All multivariate models demonstrated a significantly good fit to the data (all $\chi_{(6)}^{2}>25.5 ; \mathrm{p}<$ $0.001)$.

Finally, we conducted a post-hoc analysis (data not shown) to compare characteristics between intervention completers (i.e., 4 program sessions; $n=103$ ) and non-completers $(n=411)$. Multiracial and more educated participants were more likely to complete the full intervention (both $\mathrm{p} \leq 0.05$ ). Though results were only approaching significance (i.e., $\mathrm{p} \leq$ 0.10 ), younger participants, homeless participants, and participants without a recent history of incarceration were also more likely to complete the full intervention.

\section{Discussion}

A critical innovation of the TransAction intervention was integration of program components targeting trans-specific transitional issues, substance use, sexual risk behaviors, and HIV syndemic factors that influence risk behaviors experienced by urban trans women who experience multiple health disparities. Central to the success of the intervention was the integration of four models of behavior change (i.e., Social Cognitive Theory, Health Belief Model, Presentation of Self and Identity Management, Social Support Theory) to the intervention curriculum, with specific focus on constructs including self-esteem and selfefficacy.

The intervention targeted urban trans women facing a syndemic of HIV risk co-factors, and the participants $(\mathrm{N}=514)$ reported low income and educational attainment and high prevalence of homelessness and recent incarceration history, a sociodemographic profile 
woefully common across diverse samples of urban trans women (Bradford, Reisner, Honnold, \& Xavier, 2013; Brennan et al., 2012; Clark et al., 2018; Clements-Nolle et al., 2001; Kenagy, 2005). Furthermore, nearly one-third of participants reported a positive HIV serostatus, a prevalence rate slightly higher than similar samples of urban trans women (Brennan et al., 2012; Fletcher et al., 2014; Nemoto, Operario, Keatley, Han, \& Soma, 2004). Despite these numerous co-factors, TransAction participation was associated with significant reductions in HIV sexual and substance use-related risk behaviors. Given the positive findings from this theory-based intervention, TransAction provides a strong foundation for adaptation among high-risk trans women across the U.S. and globally, particularly within resource limited settings.

Findings from TransAction demonstrated that as program attendance increased across visits 1 through 4, prevalence of HIV sexual risk behaviors across categories decreased, including number of male sexual partners (overall, anonymous, exchange). Additionally, substance use-related HIV risk behaviors also decreased across visits 1 through 4, including engagement in injection drug use and medically unmonitored hormone use. While overall, engagement in sex work, sexual intercourse while 'high,' and alcohol/drugs use declined across TransAction attendance, there was a slight 'bounce-back' effect among participants who completed 4 visits, such that the prevalence of reported risk behaviors increased slightly at the fourth visit. The low participation in 4 visits $(n=103)$ might have led to very high-risk outliers to skew results upward. To increase TransAction attendance, future iterations might consider small monetary incentives or an intervention structure that rewards attendance, as was shown to be feasible in a small HIV risk reduction intervention among trans women (Garofalo et al., 2012). Additionally, previous syndemic research with trans women has demonstrated that substance use is significantly and positively related to both self-reported HIV infection and sexual risk behavior (Brennan et al., 2012). While we did not directly assess the association between substance use and sexual risk behaviors in this study, findings highlighted that drug/alcohol users might be at greatest risk of this 'bounce-back' effect in risk. HIV risk behaviors are compounded among trans women who suffer from substance use disorders, highlighting the need for future interventions to specifically target substance use to reduce 'bounce-back' effects. Despite this 'bounce-back' effect, regression analyses demonstrated statistical significance of the associations between TransAction attendance and every single self-reported HIV-related risk behavior. Given the demonstrated elevated HIV risk among trans women engaged in sex work (Poteat et al., 2015), substance use and injection drug use (De Santis, 2009), and sex with multiple causal and anonymous partners (Herbst et al., 2008), the ability for the intervention to strongly decrease these risk behaviors across a limited number of program visits demonstrates that TransAction is effective in reducing a host of HIV risk behaviors among trans women who experience syndemic health disparities.

Central to the success of TransAction was the 'homegrown,' low-intensity nature of the intervention. Homegrown interventions are culturally sensitive and highly relevant to their community as they are designed locally with input from the community (Rhodes et al., 2015). Trans peer staff were involved in each phase of intervention development, recruitment and facilitation. Due to the syndemic of HIV risk co-factors that high-risk trans women experience, heavily structured or high-intensity interventions are unlikely to succeed 
primarily due to lack of program adherence. TransAction is uniquely low-intensity because it is not a structured intervention whereby participants are required to follow multiple successive group or individual sessions. TransAction participants may participate in any intervention component, in any order. Other HIV interventions with high-risk participants, including men who have sex with men, have demonstrated similar success using a lowintensity, homegrown structure (Reback \& Fletcher, 2017; Rhodes et al., 2015; Vega, Spieldenner, DeLeon, Nieto, \& Stroman, 2010). Despite participants in the present study attending relatively few intervention sessions (mean number of sessions in one calendar year = 2.25), significant reductions in HIV sexual and substance-use risk behaviors associated with intervention attendance demonstrate the effectiveness of the low-intensity intervention. Clearly, given the chaotic nature of many of the participants' lives, i.e., periods of short- or long-term incarceration, experiences of homelessness, substance use disorder(s), approximately three sessions may be optimal for reducing HIV risk behaviors.

In accordance with the four models of behavior change on which the intervention was designed, self-esteem and self-efficacy were two of the central foci of TransAction. Studies with samples of high-risk trans women have demonstrated an association between low selfesteem and low self-efficacy and HIV sexual risk behaviors (Brennan et al., 2012; Operario, Nemoto, Iwamoto, \& Moore, 2011; Sugano, Nemoto, \& Operario, 2006), highlighting the importance of HIV risk reduction interventions that specifically target self-esteem and selfefficacy as key mechanisms to behavior change. More than four in five participants initiated 'self-esteem' as a discussion topic during their first visit, highlighting the pervasiveness of low self-esteem, or the desire to increase self-esteem, among the program participants. Furthermore, $15 \%$ of participants initiated 'social support' and 'emotional support' during their first visit: social support has been shown in prior studies with trans women to be closely associated with self-efficacy skills to engage in safer sex practices (Molina \& Ramirez-Valles, 2013) and, relatedly, HIV medication adherence (Johnson et al., 2006). Critical to the observed reductions in HIV risk behaviors across the program was building participants' self-esteem and social support through individual counseling sessions, targeted group sessions, and culturally tailored social events.

Given the success of TransAction in reducing HIV risk behaviors among this population, the following recommendations are suggested as core elements to any HIV risk reduction intervention targeting high-risk trans women or similarly vulnerable populations:

1. Homegrown: Interventions should be locally developed or adapted, culturally sensitive, and highly relevant to their community, with integration from community voices at all phases of intervention development and implementation.

2. Theoretically informed: Interventions should integrate evidence-based, theoretical models of behavior change to guide intervention development.

3. Low-intensity: Interventions should have limited demands and multiple pathways to participation (i.e., individual counseling, groups, events) to reduce participant burden. 
4. Self-esteem, self-efficacy and social support: Interventions should incorporate some or all of these three key mechanisms of behavior change into the curriculum.

5. Public health department support: Effective HIV risk reduction interventions targeting populations experiencing numerous co-occurring health disparities have been shown to be cost-negative (Herbst et al., 2007). Gaining institutional support from regional public health departments helps to ensure that interventions are sustainable, particularly in resource limited settings such as social service agencies and community-based organizations.

\section{Limitations \& Conclusions}

The findings from TransAction must be interpreted in light of several limitations. The findings are limited in that the program was observational, non-randomized, and there was no control group. However, the positive findings call for a future randomized controlled trial to understand the mechanism of action that influenced behavioral change. Furthermore, participation in TransAction was self-selected; thus, positive reductions in HIV risk behaviors might have been partially due to self-selection biases. The sample sociodemographics demonstrated the vulnerable nature of the participants. These findings might not be generalizeable to other samples of trans women who are less burdened by multiple co-occurring health disparities or are in less urban locations. Finally, findings from this study might be limited by the non-trivial level of missing data (i.e., 103 of 514 participants completed 4 program visits). However, similar levels of missingness have been observed in other HIV risk reduction interventions with other highly impacted samples (Reback \& Fletcher, 2017).

Despite these limitations, findings suggest that this homegrown, theory-based, low-intensity, risk-reduction intervention, which targeted the syndemic of co-occurring health disparities experienced by some trans women, was highly effective in reducing a number of HIV sexual and substance use-related risk behaviors. As the longest-running service program for trans women in Los Angeles County, TransAction has certainly demonstrated both feasibility and acceptability. TransAction provides a model for public health departments, resource limited environments, social service providers, and/or community-based organizations that aim to reduce HIV risk behaviors and transmission pathways among high-risk trans women. By tailoring a homegrown intervention to integrate responses to the syndemic of co-occurring health disparities experienced by trans women, TransAction has demonstrated the success of a HIV risk reduction intervention among this most vulnerable population.

\section{Acknowledgement}

This study was supported by the Los Angeles County, Department of Public Health, Division of HIV and STD Programs (formerly Office of AIDS Programs and Policy) contract PH\#001039. Dr. Reback acknowledges additional support from the National Institute of Mental Health (P30 MH58107). The authors thank the staff who facilitated the TransAction program, most particularly Ms. April Saravia, for their dedication and service to the trans women in Los Angeles County. 


\section{REFERENCES}

Bandura A (1991). Social cognitive theory of self-regulation. Organizational behavior and human decision processes, 50(2), 248-287.

Bandura A (2001). Social cognitive theory: An agentic perspective. Annual review of psychology, 52(1), 1-26.

Baral SD, Poteat T, Strömdahl S, Wirtz AL, Guadamuz TE, \& Beyrer C (2013). Worldwide burden of HIV in transgender women: a systematic review and meta-analysis. The lancet infectious diseases, 13(3), 214-222. doi:10.1016/S1473-3099(12)70315-8 [PubMed: 23260128]

Bockting W, Robinson B, Forberg J, \& Scheltema K (2005). Evaluation of a sexual health approach to reducing HIV/STD risk in the transgender community. AIDS care, 17(3), 289-303. [PubMed: 15832877]

Bradford J, Reisner SL, Honnold JA, \& Xavier J (2013). Experiences of transgender-related discrimination and implications for health: results from the Virginia Transgender Health Initiative Study. American journal of public health, 103(10), 1820-1829. doi:10.2105/AJPH.2012.300796 [PubMed: 23153142]

Brennan J, Kuhns LM, Johnson AK, Belzer M, Wilson EC, \& Garofalo R (2012). Syndemic theory and HIV-related risk among young transgender women: the role of multiple, co-occurring health problems and social marginalization. American journal of public health, 102(9), 1751-1757. doi:10.2105/AJPH.2011.300433 [PubMed: 22873480]

Clark K, Fletcher JB, Holloway IW, \& Reback CJ (2018). Structural Inequities and Social Networks Impact Hormone Use and Misuse Among Transgender Women in Los Angeles County. Archives of sexual behavior, 1-10. [PubMed: 28608293]

Clements-Nolle K, Marx R, Guzman R, \& Katz M (2001). HIV prevalence, risk behaviors, health care use, and mental health status of transgender persons: Implications for public health intervention. American journal of public health, 91(6), 915. [PubMed: 11392934]

De Santis JP (2009). HIV infection risk factors among male-to-female transgender persons: a review of the literature. Journal of the Association of Nurses in AIDS Care, 20(5), 362-372. doi:10.1016/ j.jana.2009.06.005 [PubMed: 19732695]

Ellemers N (1993). The influence of socio-structural variables on identity management strategies. European review of social psychology, 4(1), 27-57.

Fisher JD, \& Fisher WA (2002). The information-motivation-behavioral skills model. Emerging theories in health promotion practice and research: Strategies for improving public health, 1, 4070.

Fletcher JB, Kisler KA, \& Reback CJ (2014). Housing status and HIV risk behaviors among transgender women in Los Angeles. Archives of sexual behavior, 43(8), 1651-1661. doi:10.1007/ s10508-014-0368-1 [PubMed: 25190499]

Garofalo R, Johnson AK, Kuhns LM, Cotten C, Joseph H, \& Margolis A (2012). Life skills: evaluation of a theory-driven behavioral HIV prevention intervention for young transgender women. Journal of Urban Health, 89(3), 419-431. [PubMed: 22223033]

Glynn TR, \& van den Berg JJ (2017). A Systematic Review of Interventions to Reduce Problematic Substance Use Among Transgender Individuals: A Call to Action. Transgender health, 2(1), 4559. [PubMed: 28861547]

Grant JM, Mottet L, Tanis JE, Harrison J, Herman J, \& Keisling M (2011). Injustice at every turn: A report of the national transgender discrimination survey: National Center for Transgender Equality.

Grossman CI, Forsyth A, Purcell DW, Allison S, Toledo C, \& Gordon CM (2011). Advancing novel HIV prevention intervention research with MSM-Meeting report. Public Health Reports, 126(4), 472-479. [PubMed: 21800742]

Herbst JH, Beeker C, Mathew A, McNally T, Passin WF, Kay LS, ... Chattopadhyay S, (2007). The effectiveness of individual-, group-, and community-level HIV behavioral risk-reduction interventions for adult men who have sex with men: a systematic review. American journal of preventive medicine, 32(4), 38-67. [PubMed: 17218189]

Herbst JH, Jacobs ED, Finlayson TJ, McKleroy VS, Neumann MS, Crepaz N, \& Team HAPRS (2008). Estimating HIV prevalence and risk behaviors of transgender persons in the United States: 
a systematic review. AIDS and Behavior, 12(1), 1-17. doi:10.1007/s10461-007-9299-3 [PubMed: 17694429]

Jaffee KD, Shires DA, \& Stroumsa D (2016). Discrimination and Delayed Health Care Among Transgender Women and Men: Implications for Improving Medical Education and Health Care Delivery. Medical Care, 54(11), 1010-1016. [PubMed: 27314263]

James SE, Herman JL, Rankin S, Keisling M, Mottet L, \& Anafi M. a. (2016). The Report of the 2015 U.S. Transgender Survey.

Johnson MO, Chesney MA, Goldstein RB, Remien RH, Catz S, Gore-Felton C, ... Team NHLP. (2006). Positive provider interactions, adherence self-efficacy, and adherence to antiretroviral medications among HIV-infected adults: A mediation model. AIDS Patient Care \& STDs, 20(4), 258-268. [PubMed: 16623624]

Kenagy GP (2005). Transgender health: Findings from two needs assessment studies in Philadelphia. Health \& social work, 30(1), 19-26. [PubMed: 15847234]

Kuhns LM, Mimiaga MJ, Reisner SL, Biello K, \& Garofalo R (2017). Project LifeSkills-a randomized controlled efficacy trial of a culturally tailored, empowerment-based, and group-delivered HIV prevention intervention for young transgender women: study protocol. BMC public health, 17(1), 713. [PubMed: 28915919]

Lombardi EL, Wilchins RA, Priesing D, \& Malouf D (2002). Gender violence: Transgender experiences with violence and discrimination. Journal of homosexuality, 42(1), 89-101. doi:10.1300/J082v42n01_05

Los Angeles County Commission on HIV and the Los Angeles County Department of Public Health Division of HIV and STD Programs. (September 2016). Los Angeles County Comprehensive HIV Plan (2017-2021). Retrieved from

Molina Y, \& Ramirez-Valles J (2013). HIV/AIDS stigma: Measurement and relationships to psychobehavioral factors in Latino gay/bisexual men and transgender women. AIDS care, 25(12), 15591568. [PubMed: 23668809]

Mustanski BS, Garofalo R, \& Emerson EM (2010). Mental health disorders, psychological distress, and suicidality in a diverse sample of lesbian, gay, bisexual, and transgender youths. American journal of public health, 100(12), 2426-2432. [PubMed: 20966378]

Nemoto T, Hsueh M, Steuerman K, McCree B, \& Horne A (2007). HIV risk behaviors and substance use among transgender women in the San Francisco Bay Area. Paper presented at the 135th American Public Health Association Annual Meeting and Exposition, Washington, DC.

Nemoto T, Operario D, Keatley J, Han L, \& Soma T (2004). HIV risk behaviors among male-to-female transgender persons of color in San Francisco. American journal of public health, 94(7), 11931199. [PubMed: 15226142]

Nemoto T, Operario D, Keatley J, Nguyen H, \& Sugano E (2005). Promoting health for transgender women: Transgender Resources and Neighborhood Space (TRANS) program in San Francisco. American journal of public health, 95(3), 382-384. [PubMed: 15727962]

Nuttbrock L, Bockting W, Rosenblum A, Hwahng S, Mason M, Macri M, \& Becker J (2014). Gender abuse, depressive symptoms, and substance use among transgender women: a 3-year prospective study. American journal of public health, 104(11), 2199-2206. [PubMed: 25211716]

Operario D, \& Nemoto T (2010). HIV in transgender communities: syndemic dynamics and a need for multicomponent interventions. Journal of acquired immune deficiency syndromes (1999), 55(Suppl 2), S91. doi:10.1097/QAI.0b013e3181fbc9ec [PubMed: 21406995]

Operario D, Nemoto T, Iwamoto M, \& Moore T (2011). Unprotected sexual behavior and HIV risk in the context of primary partnerships for transgender women. AIDS and Behavior, 15(3), 674-682. [PubMed: 20740376]

Operario D, Soma T, \& Underhill K (2008). Sex work and HIV status among transgender women: systematic review and meta-analysis. JAIDS Journal of Acquired Immune Deficiency Syndromes, 48(1), 97-103. [PubMed: 18344875]

Parsons JT, Antebi-Gruszka N, Millar BM, Cain D, \& Gurung S (2018). Syndemic Conditions, HIV Transmission Risk Behavior, and Transactional Sex Among Transgender Women. AIDS and Behavior, 1-12. 
Parsons JT, Grov C, \& Golub SA (2012). Sexual compulsivity, co-occurring psychosocial health problems, and HIV risk among gay and bisexual men: further evidence of a syndemic. American journal of public health, 102(1), 156-162. [PubMed: 22095358]

Parsons JT, Millar BM, Moody RL, Starks TJ, Rendina HJ, \& Grov C (2017). Syndemic conditions and HIV transmission risk behavior among HIV-negative gay and bisexual men in a US national sample. Health Psychology, 36(7), 695. [PubMed: 28541070]

Poteat T, Wirtz AL, Radix A, Borquez A, Silva-Santisteban A, Deutsch MB, . . Operario D (2015). HIV risk and preventive interventions in transgender women sex workers. The Lancet, 385(9964), 274-286.

Raiford JL, Hall GJ, Taylor RD, Bimbi DS, \& Parsons JT (2016). The role of structural barriers in risky sexual behavior, victimization and readiness to change HIV/STI-related risk behavior among transgender women. AIDS and Behavior, 20(10), 2212-2221. [PubMed: 27167631]

Reback CJ (2005). Behavioral risk assessment [Unpublished Instrument]. Friends Research Institute, Inc. Los Angeles, CA.

Reback CJ, \& Fletcher JB (2014). HIV prevalence, substance use, and sexual risk behaviors among transgender women recruited through outreach. AIDS and Behavior, 18(7), 1359-1367. doi:10.1007/s10461-013-0657-z [PubMed: 24287786]

Reback CJ, \& Fletcher JB (2017). Outcomes from a homegrown HIV prevention program for extremely high-risk, substance-using men who have sex with men with multiple health disparities. Journal of gay \& lesbian social services, 29(2), 167-181. [PubMed: 30976151]

Reback CJ, Shoptaw S, \& Downing MJ (2012). Prevention case management improves socioeconomic standing and reduces symptoms of psychological and emotional distress among transgender women. AIDS care, 24(9), 1136-1144. doi:10.1080/09540121.2012.687817 [PubMed: 22670654]

Rhodes SD, Alonzo J, Mann L, Freeman A, Sun CJ, Garcia M, \& Painter TM (2015). Enhancement of a locally developed hiv prevention intervention for hispanic/latino MSM: A partnership of community-based organizations, a university, and the centers for disease control and prevention. AIDS Education and Prevention, 27(4), 312-332. [PubMed: 26241382]

Robinson BE, Bockting WO, Simon Rosser B, Miner M, \& Coleman E (2002). The sexual health model: application of a sexological approach to HIV prevention. Health Education Research, 17(1), 43-57. [PubMed: 11890176]

Rosenstock IM, Strecher VJ, \& Becker MH (1988). Social learning theory and the health belief model. Health education quarterly, 15(2), 175-183. [PubMed: 3378902]

Sausa LA, Keatley J, \& Operario D (2007). Perceived risks and benefits of sex work among transgender women of color in San Francisco. Archives of sexual behavior, 36(6), 768-777. doi:10.1007/s10508-007-9210-3 [PubMed: 17674180]

Schlenker BR (2012). Self-presentation. In Leary MR \& Tangey JP (Eds.), Handbook of self and identity (pp. 541-570).

Shumaker SA, \& Brownell A (1984). Toward a theory of social support: Closing conceptual gaps. Journal of social issues, 40(4), 11-36.

Singer M, \& Clair S (2003). Syndemics and public health: Reconceptualizing disease in bio-social context. Medical anthropology quarterly, 17(4), 423-441. [PubMed: 14716917]

Spicer SS (2010). Healthcare needs of the transgender homeless population. Journal of Gay \& Lesbian Mental Health, 14(4), 320-339.

Stall R, Mills TC, Williamson J, Hart T, Greenwood G, Paul J, ... Catania JA. (2003). Association of co-occurring psychosocial health problems and increased vulnerability to HIV/AIDS among urban men who have sex with men. American journal of public health, 93(6), 939-942. [PubMed: 12773359]

Stotzer RL (2009). Violence against transgender people: A review of United States data. Aggression and Violent Behavior, 14(3), 170-179.

Sugano E, Nemoto T, \& Operario D (2006). The impact of exposure to transphobia on HIV risk behavior in a sample of transgendered women of color in San Francisco. AIDS and Behavior, 10(2), 217. doi:10.1007/s10461-005-9040-z [PubMed: 16362237] 
Taylor RD, Bimbi DS, Joseph HA, Margolis AD, \& Parsons JT (2011). Girlfriends: evaluation of an HIV-risk reduction intervention for adult transgender women. AIDS Education and Prevention, 23(5), 469-478. [PubMed: 22010810]

Thoits PA (1986). Social support as coping assistance. Journal of consulting and clinical psychology, 54(4), 416. [PubMed: 3745593]

Vega MY, Spieldenner AR, DeLeon D, Nieto BX, \& Stroman CA (2010). SOMOS: evaluation of an HIV prevention intervention for Latino gay men. Health Education Research, 26(3), 407-418. [PubMed: 21059799]

White Hughto JM, Murchison GR, Clark K, Pachankis JE, \& Reisner SL (2016). Geographic and Individual Differences in Healthcare Access for US Transgender Adults: A Multilevel Analysis. LGBT health, 3(6), 424-433. [PubMed: 27636030]

White Hughto JM, Reisner SL, \& Pachankis JE (2015). Transgender stigma and health: A critical review of stigma determinants, mechanisms, and interventions. Social Science \& Medicine, 147, 222-231. [PubMed: 26599625]

Wilson E, Garofalo R, Harris RD, Herrick A, Martinez M, Martinez J, . . Interventions, A. M. T. N. f. H. A. (2009). Transgender female youth and sex work: HIV risk and a comparison of life factors related to engagement in sex work. AIDS and Behavior, 13(5), 902-913. doi:10.1007/ s10461-008-9508-8 [PubMed: 19199022]

Xavier JM, Bobbin M, Singer B, \& Budd E (2005). A needs assessment of transgendered people of color living in Washington, DC. International Journal of Transgenderism, 8(2-3), 31-47. doi:10.1300/J485v08n02_04 
Behavioral

Intervention

Behavioral Theories

Outcomes

\begin{tabular}{|l|}
\hline$\underline{\text { Social Cognitive Theory }}$ \\
-Self-regulation \\
-Self-monitoring \\
-Self-efficacy \\
-Self-esteem \\
$\underline{\text { Health Belief Model }}$ \\
-Awareness of Health \\
Risks \\
-Healthy Behaviors to \\
Reduce Risk \\
$\underline{\text { Presentation of Self and }}$ \\
$\underline{\text { Identity Management }}$ \\
- Managing Stigma \\
- Self-expression \\
$\underline{\text { Sonder Skill-building }}$ \\
-Informational \\
• Emotional \\
-Instrumental
\end{tabular}

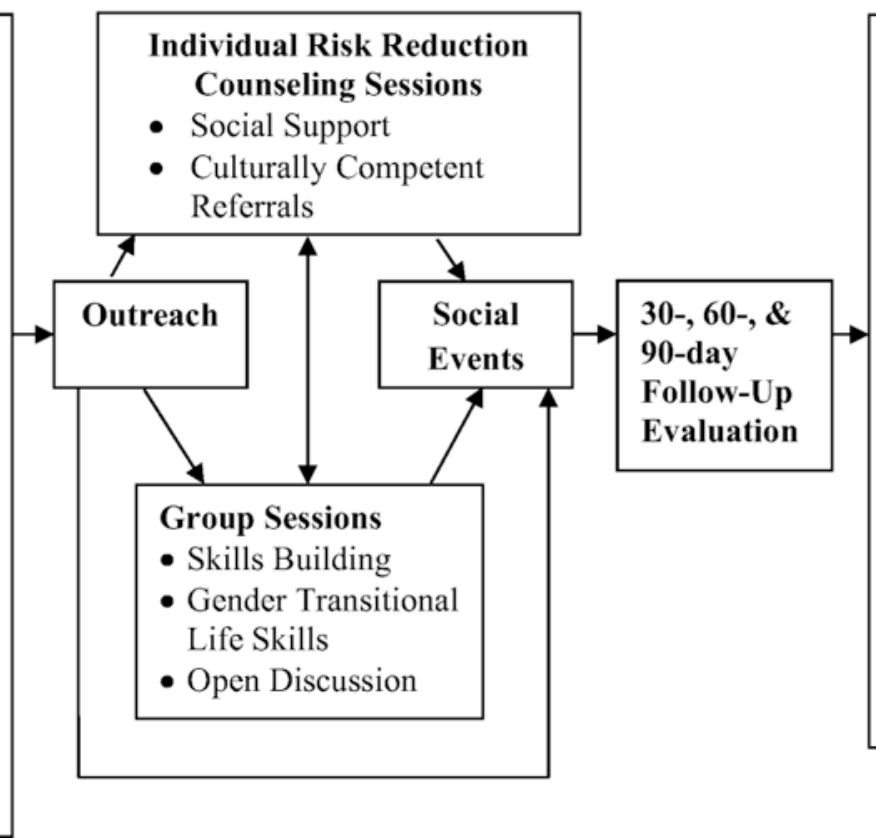

$\uparrow$ Self-efficacy

$\uparrow$ Self-esteem

$\uparrow$ Knowledge of health risks

$\uparrow$ Gender transitional life skills

$\uparrow$ Social support

$\downarrow$ Sex work

$\uparrow$ Condom use during sex work

$\uparrow$ Condom use during sex

$\downarrow$ High-risk sex behaviors

$\downarrow$ Sex while "high"

$\downarrow$ Non-injection drug use

$\downarrow$ Injection drug use

$\downarrow$ Injection non-prescribed

hormones \& hormone misuse

$\downarrow$ Sharing needles/works

$\uparrow$ Needle cleaning

$\uparrow$ Needle exchange program

$\uparrow$ Linkage to services/HIV care

Figure 1:

Conceptual framework of the TransAction program from the behavioral theories on the far left, the program design in the middle, and the behavioral change outcomes on the far right. 
Table 1:

Participant Baseline Sociodemographic Characteristics (N=514)

\begin{tabular}{|c|c|c|c|c|}
\hline Characteristic & Categories & \multicolumn{2}{|c|}{$\begin{array}{l}\mathrm{N} \text { or } \\
\text { Mean }\end{array}$} & $\begin{array}{c}\text { \% or } \\
\text { SD }\end{array}$ \\
\hline \multicolumn{5}{|c|}{ Racial/Ethnic Identity } \\
\hline & African American/Black & 160 & $31.1 \%$ & \\
\hline & Hispanic/Latina & 148 & $28.8 \%$ & \\
\hline & Caucasian/White & 64 & $12.5 \%$ & \\
\hline & Multiracial/Other & 142 & $27.6 \%$ & \\
\hline \multicolumn{5}{|l|}{ Age } \\
\hline & $(\mathrm{n}=512)$ years & 33.0 & 11.5 & \\
\hline \multicolumn{5}{|l|}{ HIV Status } \\
\hline & HIV Negative & 361 & $70.2 \%$ & \\
\hline & HIV Positive & 146 & $28.4 \%$ & \\
\hline & Don't Know & 4 & $0.8 \%$ & \\
\hline & Refused & 3 & $0.6 \%$ & \\
\hline \multicolumn{5}{|c|}{ Sexual Identity } \\
\hline & Homosexual/Gay/Lesbian & 18 & $3.5 \%$ & \\
\hline & Bisexual & 77 & $15.0 \%$ & \\
\hline & Heterosexual/Straight & 417 & $81.1 \%$ & \\
\hline & Refused & 2 & $0.4 \%$ & \\
\hline \multicolumn{5}{|c|}{ Educational Attainment } \\
\hline & Less than HS Graduate & 204 & $39.7 \%$ & \\
\hline & HS/GED Graduate & 285 & $55.5 \%$ & \\
\hline & College/Technical School Graduate & 21 & $4.1 \%$ & \\
\hline & Refused & 4 & $0.8 \%$ & \\
\hline \multicolumn{5}{|l|}{ Housing Status } \\
\hline & Housed & 244 & $47.5 \%$ & \\
\hline & Homeless & 267 & $52.0 \%$ & \\
\hline & Refused & 3 & $0.6 \%$ & \\
\hline \multicolumn{5}{|c|}{ Incarcerated (Past 12 Months) } \\
\hline & No & 359 & $69.8 \%$ & \\
\hline & Yes & 150 & $29.2 \%$ & \\
\hline & Refused & 5 & $1.0 \%$ & \\
\hline
\end{tabular}

Sex Res Social Policy. Author manuscript; available in PMC 2020 October 30. 


\section{를 \\ 골}

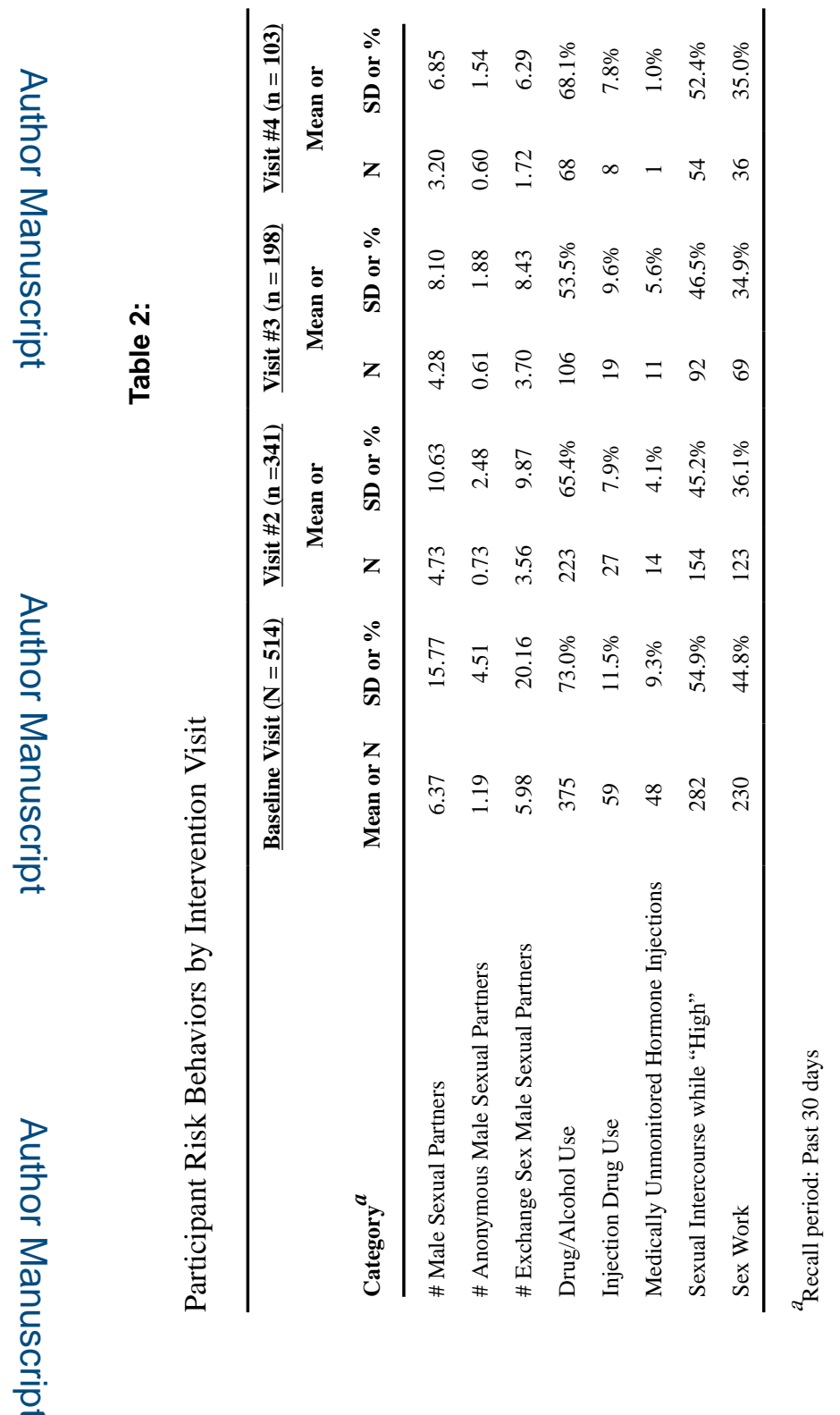

Sex Res Social Policy. Author manuscript; available in PMC 2020 October 30. 
Table 3:

Adjusted Negative Binomial and Logistic Regressions of Participant Risk Behaviors on Intervention Visit $(\mathrm{n}=$ 512)

\begin{tabular}{|c|c|c|c|c|c|c|c|c|}
\hline & \multicolumn{2}{|c|}{$\begin{array}{c}\text { \# Male } \\
\text { Sexual Partners }\end{array}$} & \multicolumn{2}{|c|}{$\begin{array}{l}\text { \# Anonymous Male } \\
\text { Sexual Partners }\end{array}$} & \multicolumn{2}{|c|}{$\begin{array}{c}\text { \# Exchange } \\
\text { Male Sexual Partners } a, b\end{array}$} & \multicolumn{2}{|c|}{ Engagement in Sex Work ${ }^{a, c}$} \\
\hline & ARR & $95 \% \mathrm{CI}$ & ARR & $95 \% \mathrm{CI}$ & ARR & $95 \% \mathrm{CI}$ & AOR & $95 \% \mathrm{CI}$ \\
\hline $\begin{array}{c}\text { Intervention Visit (1 } \\
\text { thru 4) }\end{array}$ & $-0.20^{* * *}$ & $-0.30 ;-0.09$ & $-0.25^{* *}$ & $-0.44 ;-0.06$ & $-0.25^{* * * *}$ & $-0.38 ;-0.12$ & $-0.20^{* * * *}$ & $-0.32 ;-0.09$ \\
\hline \multicolumn{9}{|c|}{ Unmonitored Injection } \\
\hline \multicolumn{5}{|c|}{ Injection Drug Use ${ }^{a c}}$, & \multicolumn{2}{|c|}{ Sex While High ${ }^{a}{ }^{c}$} & \multicolumn{2}{|c|}{ Drug/Alcohol Use ${ }^{a c}$} \\
\hline \multicolumn{9}{|c|}{ Hormone Use ${ }^{a, c}$} \\
\hline & AOR & $95 \% \mathrm{CI}$ & $\mathrm{AOR}$ & $95 \% \mathrm{CI}$ & AOR & $95 \% \mathrm{CI}$ & AOR & $95 \% \mathrm{CI}$ \\
\hline $\begin{array}{c}\text { Intervention Visit (1 } \\
\text { thru 4) }\end{array}$ & $-0.20^{*}$ & $-0.40 ; 0.00$ & $-0.55^{* * *}$ & $-0.82 ;-0.27$ & $-0.23^{* * *}$ & $-0.33 ;-0.12$ & $-0.37^{* * * *}$ & $-0.48 ;-0.25$ \\
\hline
\end{tabular}

Note: $A R R=A d j u s t e d$ Risk Ratio; $A O R=A d j u s t e d$ Odds Ratio

a Statistical Controls: Racial/Ethnic Identity, Age, HIV Status

${ }^{b}$ Cross-sectional time-series negative binomial regression (Recall period: Past 30 days)

${ }^{c}$ Cross-sectional time-series logistic regression

*

$\mathrm{p} \leq 0.05$

* $\mathrm{p} \leq 0.01$

**** $\leq 0.001$ 